\title{
India ponders the flaws exposed by plague...
}

Surat \& Bombay. Threatened with becoming an international 'no-go' area for businessmen and tourists alike, India took Herculean measures in September to control the outbreak of pneumonic plague in Surat.

Although the glare of international attention has now turned away, it is under growing pressure to act on the lessons learnt from the outbreak, in particular the need for better hygiene and sanitation facilities and for improved epidemiological monitoring.

Within 24 hours of the first reports of plague, almost all of the one million people living in the slums of Surat, which house half the city's population, had received courses of tetracycline. Vast areas were also massive 'dragnet' was set up to identify suspected cases of the plague.

It was an "amazing" effort, says David Dennis of the US Centers for Disease Control in Atlanta, Georgia, the spokesman for a team of experts sent to India by the World Health Organization (WHO) last month to investigate the outbreak.

Nonetheless, the outbreak has exposed major deficiencies in India's capacity to sprayed with flea-killing insecticides and a

carry out the critical laboratory and epidemiological studies needed during the outbreak of a rare disease. In particular, the dragnet appears to have overwhelmed the normal system of being able to prove and document what was going on.

The Indian authorities had a highly disciplined approach to collecting patient specimens. Critics claim that the problem was what happened to them afterwards. In particular, the techniques used failed accurately to identify the plague agent, Yersinia pestis, and the

\section{Dysentery, dengue fever, malarla and tuberculosis} are widespread in the slums of Surat. histochemical staining used was invalid because all the isolates were contaminated. Furthermore "they didn't have the capacity to put the organism through lab animals, or to do biochemical or bacteriophage testing", says one critic.

In its preliminary report, the WHO team recommends that India "maintains the expertise needed to deal with outbreaks of new and re-emerging diseases" and that it

\section{... as doubts over outbreak rumble on}

Surat \& Delhi. Confirmation by a team of experts set up by the World Health Organization (WHO) that the results of epidemiological studies in Surat were compatible with a limited outbreak of plague has done little to dampen scepticism among Indian microbiologists about the exact nature of the disease (see Nature 371, 547; 1994).

"The WHO team has only confirmed our suspicions," says N. P. Gupta, former director of the National Institute of Virology in Pune and one of the microbiologists who believe the outbreak was not plague. Gupta points out that the team found no evidence for pneumonic plague outside Surat, even though half a million people fled the town during the first three days of the outbreak.

But one member of the WHO team argues that pneumonic plague is not as contagious as is often claimed. He points out that, although many pathogens spread via aerosols, pneumonic plague spreads by respiratory droplets and requires close contact. "Patients in Surat died so quickly they didn't have time to contaminate others," he says.

V. V. Maleev, another member of the WHO team, says he has seen confirmed plague cases elsewhere and that the cases in Surat were not "typical". He claims that as many as half the 54 deaths attributed to plague in Surat were due to other causes.

A national committee has been set up to investigate the outbreak, chaired by $\mathrm{V}$. Ramalingaswami, former director-general of the Indian Council of Medical Research.
Its first meeting was turbulent, with many accusing the National Institute of Communicable Diseases of acting too hastily in labelling the outbreak as plague.

But one member of the WHO team argues that the uncertainty was merely the consequence of the fact that, as local laboratories used poor procedures, the original diagnosis of plague was not backed up during the outbreak itself by unequivocal identification of Yersinia pestis in cultures from blood, sputum and autopsied organs (see above).

David Dennis, from the US Centers for Disease Control in Atlanta, Georgia, and spokesman for the WHO team, says the WHO study was of necessity retrospective, and could not be expected to provide precise figures on the number of cases.

But Dennis says he is " 100 per cent sure" that pneumonic plague occurred in Surat and bubonic plague in Beed in the state of Maharashtra.

Dennis adds that the team also detected antibodies to the fraction 1 antigen of $Y$. pestis in the serum of suspected plague patients.

The working hypothesis of the WHO team, he says, is that 'secondary' pneumonic plague was introduced to Surat by an individual suffering from bubonic plague that had developed into septicaemia and subsequently seeded the lungs. This would explain why the outbreak in Surat was not preceded by an outbreak of bubonic plague.
K.S. Jayaraman \& Declan Butler strengthens relevant "surveillance, laboratory facilities and epidemiological capacities", with an implicit reference to achieving a high scientific standard.

Euvegny Tikhomirov of WHO's division of communicable diseases points out that there is a known reservoir of plague in wild rodents in parts of India that cannot be eradicated - and that wild rodents can transmit the disease to domestic rodents.

This reservoir needs to be monitored constantly, says Tikhomirov, and peoplemust be educated to notify health authorities when they notice domestic rats, which are highly susceptible to plague, dying suddenly.

But plague is only one of several infections endemic to the region. According to the United Nations Children's Fund (UNICEF) 300,000 children die each year of diarrhoea in urban areas of India alone, while dysentery, dengue fever, malaria and tuberculosis are widespread in the slums.

Other observers say that neglect of basic sanitation services keeps a disease timebomb ticking under the country. Many are also concerned that whereas 'sanitation' and 'hygiene' leapt onto the national agenda during the outbreak, this interest will subside now that the international spotlight has been turned off.

"The post-plague cleanup provided a shocking indication of what could be done," says the magazine India Today, writing of "the rare sight of municipal authorities working overtime to remove garbage and unclog sewers". The magazine claims that effective collection is prevented by widespread corruption, racketeering and inefficiency.

Surat is the diamond capital of India. It also boasts the world's largest steelworks, has a booming carpet industry and is one of the top ten contributors to the national treasury.

But 250 of the 1,250 tonnes of garbage produced daily goes uncollected, as does 60 of the 130 million litres of sewage. Industry and economics are being put before public health, complains B. D. Parmar, director of the New Civic Hospital in Surat.

Declan Butler 